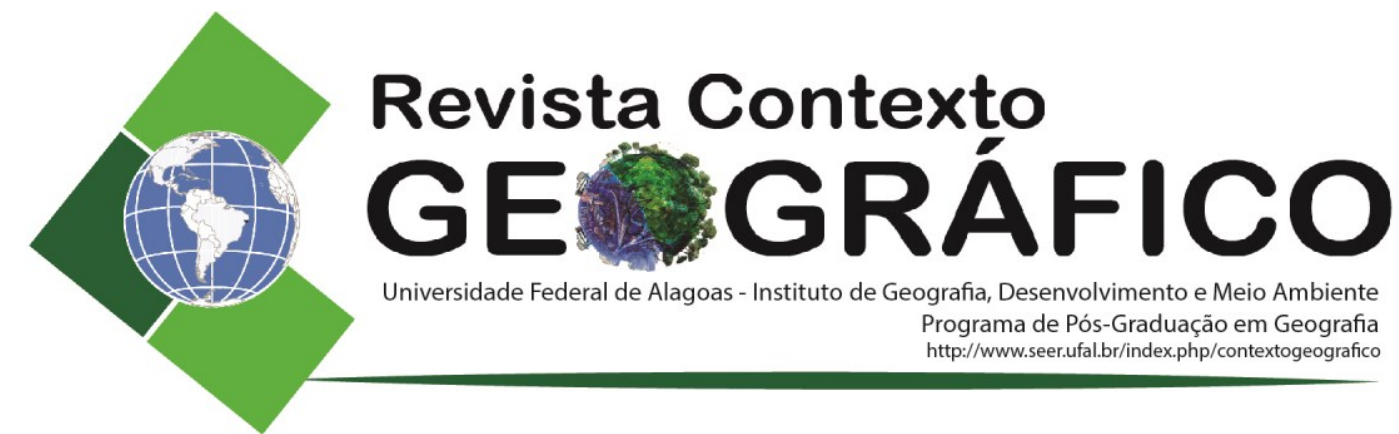

\title{
A PRODUÇ̃̃O ACADÊMICA SOBRE ESTÁGIO SUPERVISIONADO EM EDUCAÇÃO
}

\author{
Iris Lisiê Gomes Neto \\ Universidade Federal de Alagoas, Pós-Graduação em Geografia, Maceió, AL, Brasil \\ irislisiegn@gmail.com \\ Maria Francineila Pinheiro dos Santos \\ Universidade Federal de Alagoas, Pós-Graduação em Geografia, Maceió, AL, Brasil \\ francineila.pinheiro@igdema.ufal.br
}

\begin{abstract}
RESUMO - Este artigo tem por objetivo investigar a existência e/ou não de teses e dissertações sobre estágio supervisionado nos programas de pós-graduação em Educação, nas esferas federal e estadual da região Nordeste. A pesquisa realizada consubstanciou-se no método estado da arte, na qual os procedimentos metodológicos realizados compreenderam o levantamento bibliográfico nos sites das universidades federais e estaduais da região Nordeste no Brasil. Em seguida, realizou-se o download das teses e dissertações sobre estágio supervisionado no período de 2002 a 2012 . Na sequência, elaboraram-se tabelas e quadros que foram construídos a partir dos dados coletados, e por fim as análises desses dados. A análise dos dados demonstrou o número reduzido de dissertações de mestrado e teses de doutorado que tratam do estágio supervisionado nos cursos de Pós-Graduação em Educação nas universidades federais e estaduais da região Nordeste do Brasil no período de 2002 a 2012, denotando, assim, a baixa produtividade acerca dos trabalhos que discutem um componente essencial na formação inicial docente.
\end{abstract}

Palavras-chave: Prática de Ensino; estado da arte; trabalhos acadêmicos.

\section{THE ACADEMIC PRODUCTION ON SUPERVISED STAGE IN GEOGRAPHY}

\begin{abstract}
This article aims to investigate the existence and / or not of theses and dissertations on supervised internships in postgraduate programs in Education at federal and state levels in the Northeast region. The research carried out consubstantiated the state-of-the-art method, in which the methodological procedures performed included the bibliographic survey on the websites of the federal and state universities of the Northeast region of Brazil. Then, the theses and dissertations on supervised internship were downloaded from 2002 to 2012. Afterwards, tables and tables were elaborated that were constructed from the collected data, and finally the analyzes of these data. The analysis of the data showed the reduced number of master's dissertations and doctoral theses that deal with the supervised internship in the postgraduate courses in Education in the federal and state universities of the Northeast region of Brazil from 2002 to 2012, the low productivity about the works that discuss an essential component in initial teacher training.
\end{abstract}

Keywords: Teaching practice; state of art; academic work.

\section{INTRODUÇÃO}

O estágio supervisionado enquanto componente curricular obrigatório, deve proporcionar a inserção dos licenciados no ambiente escolar, às vezes pautados pelas atividades de observação, planejamento e regência de aula, buscando articular a teoria com a prática na formação docente.

Este artigo visa investigar a existência e/ou não de teses e dissertações sobre estágio supervisionado nos programas de pós-graduação em Educação, a nível federal e estadual da região Nordeste. Nosso referencial teórico está ancorado pelas autoras Pimenta e Lima (2010) e Santos (2012) que definem o estágio como uma investigação das práticas 
pedagógicas nas instituições educativas, vislumbrando a pesquisa enquanto um caminho teórico-metodológico para a formação inicial docente.

A relevância deste artigo se justifica na medida em que o estágio supervisionado é considerado o momento em que o licenciando estabelece a relação entre o conhecimento teórico e prático construído no decorrer da graduação, levando-o a exercer a docência no ambiente escolar, considerado essencial na formação inicial docente.

\title{
METODOLOGIA
}

Este artigo baseou-se na pesquisa de natureza quanti-qualitativa, que se desenvolveu a partir da pesquisa documental e bibliográfica, a fim de conhecer as produções dos programas de pós-graduação em Educação relacionada com o estágio supervisionado. Segundo Tardif (2002, p.5), "Tanto a pesquisa documental como a pesquisa bibliográfica têm o documento como objeto de investigação".

Neste sentido, adotamos o método "estado da arte", com o objetivo de verificar o que se produziu sobre o estágio supervisionado nos programas de mestrado e doutorado em Educação, nas instituições federais e estaduais da Região Nordeste, no período de 2002 a 2012.

O método Estado da Arte, segundo Fiorentini e Lorenzato (2007, p.70) "[...] se propõe a realizar análises históricas e/ou revisão de estudos ou processos tendo como material de análise documentos escritos e/ou produções culturais". Inventariar produções acadêmicas de diversas áreas do conhecimento em busca de respostas a diferentes problemáticas tem mobilizado pesquisadores a desenvolverem estudos bibliográficos da produção acadêmica.

\begin{abstract}
O estado da arte é uma das partes mais importantes de todo trabalho científico, uma vez que faz referência ao que já se tem descoberto sobre o assunto pesquisado, evitando que se perca tempo com investigações desnecessárias. Além disso, auxilia na melhoria e desenvolvimento de novos postulados, conceitos e paradigmas (COSTA, 1996, p.17).
\end{abstract}

Para Fiorentini e Lorenzato, (2007, p.70) o estado da arte "[...] pode ser entendido como uma pesquisa de revisão, a qual se propõe a realizar análises históricas e/ou revisão de estudos ou processos tendo como material de análise documentos escritos e/ou produções culturais", contribuindo no mapeamento das produções acadêmicas de diferentes áreas do conhecimento.

Conforme Ferreira (2002) os trabalhos de pesquisa denominados estado da arte constituem-se em inventários descritivos, cujo principal objetivo é o de criar um quadro panorâmico das pesquisas realizadas em torno de temas específicos.

Para a consecução dos objetivos visitamos os sites das Universidades Federais e Estaduais da Região Nordeste que disponibilizavam respectivamente o mestrado e doutorado em Educação, buscando analisar as discussões acerca do estágio supervisionado na última década.

O percurso metodológico deste trabalho envolveu três fases. Na primeira fase realizamos um levantamento no site dos programas de pós-graduação em Educação das universidades federais e estaduais da região nordeste brasileira.

Na segunda fase, fizemos download das teses e dissertações produzidas no Nordeste brasileiro, as quais seus títulos apresentassem de estágio supervisionado, durante o período de 2002 a 2012. Consultamos os sites das instituições para verificar se o estágio tem se apresentado como objeto de estudo, fazendo-se download dos resumos para a leitura e identificação do quadro teórico, do método utilizado e das conclusões, buscando também, analisar possíveis similitudes entre as pesquisas e quais assuntos e temas são recorrentes. 
$\mathrm{Na}$ terceira fase elaboramos tabelas e quadros que foram construídos a partir dos dados coletados. E por fim realizamos as análises dos dados expostos.

\section{RESULTADOS E DISCUSSÕES}

O estágio supervisionado se caracteriza como sendo, todas as "atividades de aprendizagem social, profissional e cultural, proporcionadas ao estudante pela participação em situações reais de vida e trabalho" (Art. $2^{\circ}$ do decreto de $n^{\circ}$ 87.497, de 18.08.82). Compreender o que representa o estágio para a formação inicial é uma questão fundamental para vivenciá-lo na prática do cotidiano educacional, ou seja, para a profissão docente.

Nesse contexto, Passini (2007, p. 27) ressalta que "A Prática de Ensino e Estágio Supervisionado estão presentes em todos os cursos de licenciatura, devem ser considerados como a instrumentalização fundamental no processo de formação profissional de professores", denotando a importância do estágio enquanto momento propício para as discussões e reflexões sobre a prática do docente de Geografia. Sendo assim, o estágio supervisionado enquanto componente curricular obrigatório, deve proporcionar a inserção dos licenciados no ambiente escolar, às vezes pautados pelas atividades de observação, planejamento e regência de aula, buscando articular a teoria com a prática na formação docente.

Nesta perspectiva, Buriolla (2009, p. 13, apud SANTOS, 2012, p.119), afirma que, "o estágio é o lócus onde a identidade profissional é gerada, construída e referida; volta-se para o desenvolvimento de uma ação vivenciada, reflexiva e crítica e, por isso, deve ser planejado gradativa e sistematicamente com essa finalidade", gerando consequentemente uma reflexão crítica sobre o que é ser professor, teorizando sobre sua própria formação docente.

Pimenta e Lima (2010, p. 29) apontam que ao pensar o estágio enquanto local propício para a pesquisa acabou por atribuí-lo a "[...] um estatuto epistemológico que visa superar a sua tradicional redução à atividade prática instrumental".

Desse modo, concordamos com o pensamento da autora, a qual corrobora com Santos (2012, p. 14) ao salientar que o "[...] estágio enquanto espaço de pesquisa viabiliza uma qualitativa formação inicial do docente de Geografia, consubstanciada na articulação teoria-prática, no fortalecimento da identidade docente e na formação do professor-pesquisador". Com base no exposto pelas autoras, entendemos que o estágio supervisionado deve ser considerado como um dos principais momentos de desenvolvimento na formação inicial docente.

Ademais, ambas as autoras se debruçam sobre o estagio supervisionado enquanto objeto de estudo, defendendo o mesmo como um espaço privilegiado, o qual proporciona aos discentes a articulação entre a teoria-prática e a construção de sua identidade profissional.

Os cursos de Pós-Graduação em Educação nas Universidades Federais, em nível de mestrado acadêmico e/ou doutorado, na região Nordeste, encontram-se presentes nos seguintes estados (figura 1).

Figura 1: Universidades federais da região nordeste que possuem programa de pós-graduação em Educação, reconhecidos pela Coordenação de Aperfeiçoamento de pessoal - (CAPES).

\begin{tabular}{|c|c|c|}
\hline Universidades Federais do Nordeste & Mestrado & Doutorado \\
\hline Universidade Federal de Alagoas - UFAL & $\mathrm{X}$ & $\mathrm{X}$ \\
\hline Universidade Federal da Bahia - UFBA & $\mathrm{X}$ & $\mathrm{X}$ \\
\hline
\end{tabular}




\begin{tabular}{|c|c|c|}
\hline Universidade Federal do Ceará - UFC & X & X \\
\hline Universidade Federal do Maranhão - UFMA & $\mathrm{X}$ & - \\
\hline Universidade Federal da Paraíba - UFPB & $\mathrm{X}$ & $\mathrm{X}$ \\
\hline Universidade Federal de Pernambuco - UFPE & $\mathrm{X}$ & $\mathrm{X}$ \\
\hline Universidade Federal do Piauí - UFPI & $\mathrm{X}$ & $\mathrm{X}$ \\
\hline Universidade Federal do Rio Grande do Norte - UFRN & $\mathrm{X}$ & $\mathrm{X}$ \\
\hline Universidade Federal de Sergipe - UFSE & $\mathrm{X}$ & $\mathrm{X}$ \\
\hline & 9 & 8 \\
\hline
\end{tabular}

Fonte: http://www.capes.com.br/

Elaboração: NETO, (2013).

A figura 1 demonstra que com exceção da Universidade Federal do Maranhão, a qual só possui mestrado em Educação, todas as outras possuem mestrado e doutorado em Educação, reconhecidos pela CAPES.

Após a análise da produção científica dos programas de Pós-Graduação em Educação listadas na figura 1, selecionamos apenas as teses e/ou dissertações relacionada ao estágio supervisionado, das quais iremos destacar 2 teses e 9 dissertações.

A figura 2 mostra os títulos das teses e dissertações produzidas pelos programas de PósGraduação em Educação dentro do recorte temporal estabelecido pela pesquisa.

Figura 2: Teses e dissertações relacionadas ao estágio supervisionado na Pós-Graduação em Educação nas universidades federais do nordeste brasileiro (2002-2012).

\begin{tabular}{|c|c|c|c|}
\hline $\begin{array}{c}\text { Universidades } \\
\text { Federais }\end{array}$ & \multicolumn{2}{|c|}{$\begin{array}{c}\text { Trabalhos } \\
\text { Produzidos }\end{array}$} & Títulos \\
\hline \multirow{2}{*}{$\begin{array}{c}\text { Universidade } \\
\text { Federal do Ceará } \\
\text { (UFC) }\end{array}$} & Mestrado Doutorado & 1 & $\begin{array}{c}\text { A prática de ensino e o estágio supervisionado na } \\
\text { construção de saberes e competências didático- } \\
\text { pedagógicas: O caso da UFPI. }\end{array}$ \\
\cline { 2 - 5 } & 1 & - & $\begin{array}{c}\text { Percepção da escola-campo sobre o estágio } \\
\text { supervisionado em biologia: Contribuições para uma } \\
\text { avaliação curricular. }\end{array}$ \\
\hline $\begin{array}{c}\text { Universidade } \\
\text { Federal do } \\
\text { Maranhão } \\
\text { (UFMA) }\end{array}$ & 1 & - & $\begin{array}{c}\text { Formação de professores de ciências biológicas: Um } \\
\text { estudo de caso a partir dos estágios supervisionados }\end{array}$ \\
\hline $\begin{array}{c}\text { Universidade } \\
\text { Federal da } \\
\text { Paraíba } \\
\text { (UFPB) }\end{array}$ & 1 & - & $\begin{array}{c}\text { Estágio Curricular não-obrigatório: Limites e } \\
\text { perspectivas na formação dos estudantes para o mundo } \\
\text { do trabalho. }\end{array}$ \\
\cline { 2 - 5 } & 1 & - & $\begin{array}{c}\text { O estágio supervisionado e formação de profissionado curso de pedagogia do CFP/UFCG } \\
\text { técnico em agropecuária no IFPB, Sousa, PB. }\end{array}$ \\
\hline
\end{tabular}




\begin{tabular}{|c|c|c|c|}
\hline $\begin{array}{c}\text { Universidade } \\
\text { Federal Rural de } \\
\text { Pernambuco } \\
\text { (UFRPE) }\end{array}$ & 1 & - & $\begin{array}{l}\text { Os desafios do estágio supervisionado no curso de } \\
\text { licenciatura em ciências biológicas da UFRPE. }\end{array}$ \\
\hline $\begin{array}{l}\text { Universidade } \\
\text { Federal de } \\
\text { Pernambuco } \\
\text { (UFPE) }\end{array}$ & 1 & - & $\begin{array}{l}\text { O estágio e a política de formação do educador: Um } \\
\text { estudo a partir de programas e projetos da rede } \\
\text { municipal de ensino do Recife. }\end{array}$ \\
\hline $\begin{array}{c}\text { Universidade } \\
\text { Federal do Rio } \\
\text { Grande do Norte } \\
\text { (UFRN) }\end{array}$ & - & 1 & $\begin{array}{l}\text { Estágio Supervisionado na Formação de Professores em } \\
\text { serviço dos anos iniciais do Ensino Fundamental. }\end{array}$ \\
\hline \multirow{2}{*}{$\begin{array}{c}\text { Universidade } \\
\text { Federal de Sergipe } \\
\text { (UFS) }\end{array}$} & 1 & - & $\begin{array}{c}\text { Formação da identidade docente: } \\
\text { Estágio supervisionado, memórias e representações } \\
\text { sociais. }\end{array}$ \\
\hline & 1 & - & $\begin{array}{l}\text { Divisão social do trabalho e alienação na formação de } \\
\text { professores de educação física da UFS: O } \\
\text { estágio supervisionado/prática de ensino enquanto } \\
\text { síntese dialética dos projetos em disputa. }\end{array}$ \\
\hline Total & 9 & 2 & - \\
\hline
\end{tabular}

Fonte: http://www.capes.com.br/

Organização: NETO, (2013).

De acordo com a figura 2 temos no total de 9 trabalhos de mestrado que apresentaram em seus títulos o estágio supervisionado. Assim como um total de 2 teses, onde identificamos em seu título o estágio, evidenciando uma baixa produção nos programas de pós-graduação em Educação no que diz respeito ao supracitado tema.

É importante destacar que das universidades pesquisadas, a Universidade Federal de Alagoas é a única universidade da região Nordeste, com pós-graduação em Educação, que não disponibiliza a produção de seus discentes no site do seu programa.

No que se refere a análise dos resumos das teses de doutorado, constatamos que somente dois trabalhos abordaram a referida temática, no qual um centrava a discussão sobre a prática docente, e o outro sobre a formação docente.

Em relação os resumos das dissertações de Mestrado, o tema mais recorrente foi a prática docente aparecendo em 7 resumos, e em seguida se destacou a formação docente, aparecendo em 5 dissertações. É importante destacar que em algumas dissertações essas temáticas apareceram interligadas.

Sendo assim, podemos afirmar que embora a produção tenha sido menor nos cursos de doutorado, as temáticas que se sobressaem tanto no doutorado como no mestrado, são as mesmas, notadamente: prática docente e formação docente, ambas diretamente interligadas com o período de realização do estágio supervisionado nos cursos de graduação em licenciatura.

O Estágio supervisionado é para muitos licenciados, o momento em que os mesmos se inserem no ambiente escolar, exercendo a prática docente. Neste sentido, Pimenta (2005, p. 17-18) ressalta que neste período é preciso ampliar nos "alunos conhecimentos e habilidades,

$\begin{array}{lllll}\text { ReVista Contexto Geográfico } & \text { Maceló-AL } & \text { V. 2. N.4 } & \text { DeZembro/2017 } & \text { P. } 104-112\end{array}$ 
atitudes e valores que lhes possibilitem permanentemente irem construindo seus saberesfazeres docentes a partir das necessidades e desafios que o ensino com prática social lhes coloca no cotidiano". A prática docente é uma construção cotidiana que envolve professor e alunos e desenvolve principalmente os conhecimentos adquiridos por ambos e assim se desenvolve o processo de ensino e aprendizagem.

Neste contexto, a escola é o lugar onde todas essas trocas são possíveis e o momento do estágio supervisionado é crucial para a consecução da profissão docente. Segundo Tardif (2002, p.196), a escola influencia de maneira decisiva na prática docente, pois o educador precisa compreender que essa é "[...] uma tarefa dinâmica com efeitos imprecisos e longínquos que requerem a iniciativa dos professores; estes precisam interpretá-los e adaptálos constantemente aos contextos movediços da ação pedagógica". Corroboramos com o pensamento do autor ao passo que destacamos a importância da escola no desenvolvimento da atividade docente, o contato do docente não é apenas com os alunos em sala de aula, mas com todos os envolvidos no sistema educacional.

Assim sendo, a prática docente precisa se pautar na construção de saberes. Segundo Castellar (2010, p. 56) deve objetivar “[...] não só dominar conteúdos, mas ter, ao mesmo tempo, um discurso conceitual organizado com uma proposta adequada de atividade, buscando superar os obstáculos da aprendizagem". De acordo com a autora, dominar o conteúdo, ainda que seja importante, não é o suficiente para a construção de uma prática docente efetiva. O docente é desafiado diariamente a criar novas abordagens metodológicas que facilitem a aprendizagem, mantendo a qualidade de ensino.

No que diz respeito à Formação Docente, a mesma deve funcionar como uma articuladora entre os processos teóricos vividos da academia e os processos práticos que aconteceram no momento do estágio supervisionado. Segundo Castellar (2010, p. 40) os cursos de formação docente não devem focar somente nos aspectos teórico da disciplina, mas também têm que se preocupar em "[...] incorporar referenciais no campo das dimensões econômicas, sociais e culturais, com uma visão de mundo que incorpore o lugar onde vivem os alunos e docentes, as singularidades e os conflitos de valores". Concordamos com a autora ao passo que evidenciamos a importância do docente promover em seus educandos um momento de reflexão acerca do contexto espacial, geográfico, político entre outros, para que se estabeleçam vínculos entre a escola e o ambiente social onde estão inseridos.

A análise dos resumos dos trabalhos explicitados na figura 2 salienta o desafio da prática docente durante o estágio, e os saberes docentes adquiridos nessa fase acadêmica. Discute ainda a formação dos professores durante os anos iniciais do ensino fundamental e as dificuldades apresentadas durante o estágio supervisionado realizado em sala de aula.

Em relação as universidades estaduais localizadas na região Nordeste, somente três dos nove estados nordestinos dispõe de programas de Pós-Graduação em Educação, conforme evidenciamos na figura 3.

Figura 3: Universidades Estaduais que oferecem mestrado e doutorado, em Educação, reconhecidos pela CAPES.

\begin{tabular}{|c|c|c|c|}
\hline UF & $\begin{array}{c}\text { Universidades Estaduais do Nordeste - Programa de } \\
\text { Pós Graduação em Educação }\end{array}$ & Mestrado & Doutorado \\
\hline BA & Universidade Estadual da Bahia - UNEB & $\mathrm{x}$ & $\mathrm{x}$ \\
\hline BA & Universidade Estadual de Feira de Santana - UEFS & $\mathrm{x}$ & - \\
\hline BA & Universidade do Sudoeste da Bahia - UESB & $\mathrm{x}$ & - \\
\hline
\end{tabular}




\begin{tabular}{|c|c|c|c|}
\hline $\mathrm{CE}$ & Universidade Estadual do Ceará - UECE & $\mathrm{x}$ & $\mathrm{x}$ \\
\hline $\mathrm{RN}$ & Universidade Estadual do Rio Grande do Norte - UERN & $\mathrm{x}$ & - \\
\hline & & $\mathbf{5}$ & $\mathbf{2}$ \\
\hline
\end{tabular}

\section{Fonte: http://www.capes.gov.br/. \\ Organização: NETO, (2013).}

A figura 3 demonstra que apenas três estados da região nordeste são contemplados com programas de pós-graduação em Educação nas suas universidades estaduais. São eles os estados da Bahia, Ceará e Rio Grande do Norte. Desse modo, dos três estados que dispõe de programas de pós-graduação, o estado da Bahia possui 3 cursos de mestrado e 1 de doutorado. O estado do Ceará dispõe de 1 mestrado e 1 doutorado, enquanto o estado do Rio Grande do Norte só apresenta um curso de mestrado.

No que diz respeito à produção científica dos programas de Pós-Graduação em Educação a nível estadual, selecionamos as teses e dissertações relacionada ao estágio supervisionado, das quais dispomos de uma tese e três dissertações.

Figura 4: Teses e dissertações relacionadas ao estágio supervisionado na Pós-

Graduação em Educação nas universidades estaduais do nordeste brasileiro (2002-2012).

\begin{tabular}{|c|c|c|c|}
\hline \multirow{2}{*}{$\begin{array}{l}\text { Universidades } \\
\text { Estaduais }\end{array}$} & \multicolumn{2}{|c|}{ Trabalhos Produzidos } & \multirow[b]{2}{*}{ Títulos } \\
\hline & Mestrado & Doutorado & \\
\hline \multirow{3}{*}{$\begin{array}{l}\text { Universidade do Estado } \\
\text { da Bahia (UNEB) }\end{array}$} & 1 & - & $\begin{array}{l}\text { Estágio Supervisionado e Narrativo } \\
\text { (Auto) Biográficas: Experiências de } \\
\text { Formação Docente. }\end{array}$ \\
\hline & 1 & - & $\begin{array}{l}\text { Formação Inicial e Construção de Saberes } \\
\text { Profissionais Docentes: Um Estudo de } \\
\text { Caso do Seio do Programa Rede UNEB } \\
2000 .\end{array}$ \\
\hline & - & 1 & $\begin{array}{l}\text { O Conhecimento de Si: Narrativas do } \\
\text { Itinerário Escolar e Formação de } \\
\text { Professores. }\end{array}$ \\
\hline $\begin{array}{l}\text { Universidade Estadual } \\
\text { do Ceará (UECE) }\end{array}$ & 1 & - & $\begin{array}{l}\text { Docência no ensino superior: professores } \\
\text { formadores e sua formação. }\end{array}$ \\
\hline
\end{tabular}

Fonte: http://www.capes.gov.br/.

Organização: NETO, (2013).

De acordo com a figura 4 podemos observar que tanto a Universidade Estadual do Ceará UECE, quanto a Universidade Estadual da Bahia - UNEB, apresentam em suas produções, as mesmas temáticas relacionadas ao estágio supervisionado, encontradas nos programas de pósgraduação em nível federal, as quais compreendem a formação do professor e a prática docente.

Levando em consideração a análise dos resumos dos trabalhos expostos na figura 4, o estágio supervisionado encontra-se consubstanciado na concepção de Pimenta e Lima (2010), demonstrando que a referida autora se apresenta enquanto referencial teórico na discussão da temática em foco.

Atualmente as discussões levantadas sobre formação docente, indicam a importância de um trabalho reflexivo no exercício docente. Nesse contexto, Nóvoa (1992), nos leva a refletir que a formação de professores, se dá embasada tambem na (re) construção de saberes, sendo por isso, 
muitas vezes salientado que o professor aprende diariamente em sala de aula. A busca por uma proposta metodológica diferenciada estimula os discentes a inovar sua maneira de trabalhar e tornar o curso mais produtivo, criando uma relação mais estreita com seus educandos. Situação perfeita para o desenvolvimento de uma autonomia profissional.

Libâneo (2002) considera que os professores formado na perspectiva do trabalho reflexivo se apresentam cada vez mais envolvidos também nos processos de formação de seus alunos numa perspectiva ética, de cidadania, de compromisso com a elaboração de uma sociedade mais justa e igualitária Concordamos com o referido autor, ao passo que afirmamos que o estágio supervisionado oferece condições para que essa consideração se estabeleça.

Apesar da baixa quantidade de teses e dissertações que abordam o tema Estágio Supervisionado nos cursos de Pós-Graduação em Educação nas universidades federais e estaduais da região Nordeste no período de 2002 a 2012, o mesmo não ocorre nas demais Regiões. Pois, de acordo com Pinheiro (2005, p.102), os estudos envolvendo o estágio supervisionado em Geografia têm apresentado um considerável crescimento de publicações, inclusive trabalhos com "[...] propostas de articulação entre a prática de pesquisa e a prática do estágio como meio de inserção dos futuros professores nas escolas de ensino básico". No entanto, nos parece que esta produção se resume a congressos, livros e artigos e não necessariamente a pós-graduação, denotando a importância de discutirmos mais sobre essa etapa essencial da formação inicial docente.

\section{CONSIDERAÇÕES FINAIS}

Embora muitos trabalhos referentes a estágio supervisionado sejam publicados em eventos científicos, a nossa pesquisa demonstrou que o tema Estágio Supervisionado nos cursos de PósGraduação em Educação nas universidades federais e estaduais da região Nordeste no período de 2002 a 2012 predomina a baixa quantidade de trabalhos, confirmando o pouco interesse pela referida temática, a qual é extrema relevante para a formação inicial docente.

Este artigo demonstra que o estágio supervisionado vem sendo pouco evidenciado nos programas de pós-graduação, o que nos preocupa, mas ao mesmo tempo nos instiga a continuar os estudos acerca desta temática, pois se acredita que esta é uma etapa imprescindível da formação inicial docente e por isso carece de mais discussões e reflexões teóricas acerca da mesma.

Sendo assim, considero o estágio supervisionado enquanto disciplina fundamental na formação de professores, tendo em vista consistir na oportunidade de articulação da teoria e prática na construção dos conhecimentos geográficos. Esse momento propicia reflexões, as quais nortearão a profissão docente dos licenciandos, em face que muitos deles iniciam no estágio supervisionado a sua inserção no ambiente escola, dando inicio a construção da sua identidade docente.

É fundamental que o discente dos cursos de pós-graduação discuta temas que se encontram no currículo de formação do professor, notadamente o estágio supervisionado, pois pensar nestas questões possibilita desenvolver princípios científicos cada vez mais relevantes para a docência.

O estágio supervisionado é o momento de promover a prática docente, buscando uma formação inicial docente de qualidade para que futuramente os licenciados possam admitir uma postura ética e profissional em sala de aula. Nesta perspectiva, é que o estágio supervisionado é visto como momento propício para discutir a relação teoria e prática com vista à educação para a cidadania.

\section{AGRADECIMENTOS}


Este artigo é resultante de parte da pesquisa intitulada: "Estado da Arte: pesquisas sobre estágio supervisionado em Geografia nas universidades federais e estaduais da região Nordeste/Brasil no período de 2002-2012”, financiada pelo Programa Institucional de Bolsas de Iniciação Cientifica - PIBIC. Desse modo, meus agradecimentos a CNPq e FAPEAL que possibilitou o desenvolvimento dessa pesquisa.

\section{REFERÊNCIAS}

BRASIL. Coordenação de Aperfeiçoamento de Pessoal de Nível Superior. Disponível em: $<$ http://www.capes.gov.br/>Acesso em 09/03/2013.

BURIOLLA, Marta A. F. O estágio supervisionado. 6. ed. São Paulo: Cortez, 2009.

CASTELLAR, S. M. V. Educação geográfica: formação e didática. In: MORAIS, E. M. B. de; MORAES, L. B. (Orgs.) Formação de professores: conteúdos e metodologias no ensino de geografia. Goiânia: NEPEG, 2010.

COSTA, O. T. da. Participação dos trabalhadores nos lucros e resultados da empresa. Revista do Tribunal Regional do Trabalho da $8^{\text {a }}$ Região, Belém, v. 29, n. 57, p. 11-20, jul./dez, 1996.

FERREIRA, N. S. de A. As pesquisas denominadas "estado da arte". Revista Educação \& Sociedade, Campinas, n. 79, p. 257-272, Ago, 2002.

FIORENTINI, D.; LORENZATO, S. Investigação em educação matemática - percursos teóricos e metodológicos. ( $2^{\mathrm{a} e d i c ̧ a ̃ o) . ~ C a m p i n a s: ~ A u t o r e s ~ A s s o c i a d o s, ~} 2007$.

LIBÂNEO, J. C. Reflexidade e formação de professores: outra oscilação do pensamento pedagógico brasileiro? In: PIMENTA, Selma Garrido, Evandro. Professor reflexivo no Brasil: Gênese e crítica de um conceito. São Paulo: Cortez,2002.p.53-77.

NÓVOA, A. Formação de professores e profissão docente. In: Os Professores e a sua formação. Lisboa: Nova Enciclopédia, publicações Dom Quixote, 1992. (Coleção Temas de Educação, 39).

PASSINI, Elza Yasuko. Alfabetização cartográfica. In: PASSINI, Elza Yasuko. Prática de Ensino em Geografia e Estágio Supervisionado. São Paulo: Contexto, 2007.

PIMENTA, S. G. Formação de professores: identidade e saberes da docência. In: Saberes pedagógicos e atividade docente. $4^{\mathrm{a}}$ Ed, São Paulo: Cortez, 2005.

PIMENTA, S. G.; LIMA, M. S. L. Estágio e docência. 5. ed. São Paulo: Cortez, 2010.

PINHEIRO, A. C. O Ensino de Geografia no Brasil. Goiânia: Vieira, 2005.

SANTOS, M. F. P. dos. O estágio enquanto espaço de pesquisa: caminhos a percorrer na formação docente em Geografia. Porto Alegre, 2012. 130fl. Tese (Doutorado) - Instituto de Geociências da Universidade Federal do Rio Grande do Sul (UFRGS), 2012.

TARDIF, M. Saberes Docentes e Formação Profissional. Petrópolis: Vozes, 2002. 